\title{
Entre a prática e a teoria: algumas propostas para pensar o ensino em publicidade
}

\author{
Milena Carvalho B. F. de Oliveira-Cruz*
}

\author{
Juliana Petermann**
}

Resumo: Este artigo busca refletir acerca das práticas e saberes que orientam a formação do profissional da publicidade. Parte-se do princípio que existe, na construção da identidade do publicitário, o estereótipo de um sujeito mais alinhado às práticas do que às formulações teóricas. Assim, pretende-se debater de que maneira esta imagem é construída e como acaba por interferir na formação e atuação profissional e acadêmica destes sujeitos. Ainda, sugere refletir se (e como) a academia contribui com esta constituição.

Palavras-chave: publicidade; ensino; formação profissional e acadêmica.

Resumen: Este artículo visa reflexionar sobre las prácticas y saberes que orientan la formación del profesional de la publicidad. Partimos de lo principio que existe, en la construcción de la identidad del publicitario, el esteriotipo de un individuo mas en línea con la práctica que la teoría. Así, pretendemos discutir de que manera esta imagen es construida y como interfiere en la formación y la actuación profesional y académica de esos individuos. Además, sugerimos reflexionar si (y como) la academia contribuye con esta constitución.

Palabras claves: publicidad; enseño; formación profesional y académica.

Abstract: This article aims at reflecting on practices and knowledge that guide the formation of professionals in advertising. We base our reflexion on the principle that the image of the advertising person is constructed from the stereotype existent of a person more lined up to the practices than the theoretical formulations. Therefore, we intend to discuss how this image is built and how it interferes in their formation and professional and academic performance. Moreover, we pretend to reflect on whether (and how) the academy helps with building such an image.

Keywords: advertisement; education; professional and academic formation 
Não são recentes os estudos que se dedicam a analisar as significações e contradições que permeiam a complexa relação entre publicidade e sociedade. Considerando que há muito a interferência da publicidade no âmbito social ultrapassa os limites de sua atuação visivelmente mercadológica, partimos da sua caracterização enquanto instituição social (GOLOBOVANTE, 2005, p. 144), que orienta, antecipa ou produz valores e modelos de comportamento.

Neste contexto, entendemos ser necessário ponderar os discursos valorativos extremados que condenam ou enaltecem a prática publicitária e seus efeitos, tão comuns entre os estudos sobre o assunto. Pensar a prática publicitária com acuidade implica em observar a vinculação de seu discurso às forças sociais que o condicionam e o contextualizam. Sendo preciso considerar, ainda, as ambigüidades e contradições que permeiam a relação dos sujeitos, nas suas práticas sócio-culturais, com esse discurso (PIEDRAS \& JACKS, 2005, p. 203).

Tendo como princípio a importância do olhar cauteloso sobre estes sujeitos que compõem a trama que relaciona publicidade e sociedade, nos detemos a observar o lugar construído e ocupado por aquele cuja função está na elaboração deste discurso: o publicitário. Refletir sobre o profissional de publicidade sugere a análise de suas práticas, seus valores e sua identidade. Entendemos, neste contexto, que a reflexão sobre a formação acadêmica na construção deste publicitário enquanto sujeito, revelado a partir de seu ofício e de sua função social, assume grande relevância.

Assim, discutir a formação acadêmica é indissociável do pensamento sobre a construção identitária e sobre o lugar ocupado pelo profissional da área perante a sociedade. É com este intuito, inclusive, que os Planos Políticos Pedagógicos dos cursos superiores direcionam suas matrizes curriculares com vistas ao perfil do egresso, do profissional que vai atuar elaborando a mensagem publicitária, efetivamente. É sabido que a formação acadêmica na área de Publicidade e Propaganda não é exigida para atuação no mercado profissional, no contexto brasileiro. Não é nosso intuito, contudo, discutir a necessidade da formação universitária para o desempenho da profissão (embora reconheçamos a importância deste tema, o debate fugiria dos limites possíveis da reflexão proposta para este ensaio).

O que consideramos preponderante é refletir sobre "como" esta formação está diretamente ligada ao papel assumido pelo publicitário em nossa sociedade: "como" a construção deste perfil profissional é per- 
meada por valores construídos na relação entre academia, mercado e sociedade. Desta feita, tomamos como base as Diretrizes Curriculares para os cursos de Comunicação Social no Brasil (Parecer CNE/CES 492-2001, p.15-16) para observar alguns atributos que são tidos como parâmetro para o perfil comum do profissional de comunicação:

utilizar criticamente o instrumental teórico-prático oferecido em seu curso, sendo portanto competente para posicionar-se de um ponto de vista ético-político sobre o exercício do poder na comunicação, sobre os constrangimentos a que a comunicação pode ser submetida, sobre as repercussões sociais que enseja e ainda sobre as necessidades da sociedade contemporânea em relação à comunicação social.

Vemos, portanto, que as Diretrizes Curriculares apontam para a formação de um sujeito crítico, capaz de posicionar-se, de compreender a relevância e a repercussão de sua atuação profissional. Tomando este referente como base na formação destes sujeitos, passamos a analisar o quanto este perfil se aproxima daquele que é construído e observado tanto pela sociedade, quanto pelo próprio profissional da área.

Parte-se do princípio que existe, na construção da identidade do publicitário, o estereótipo de um sujeito mais alinhado às práticas do que às formulações teóricas. Para refoçar esta idéia, recorremos a Roberto Menna Barreto quando exempifica a incompatibilidade entre o publicitário criativo e as "lucubrações dos teóricos":

Ney Figueiredo, um bem-sucedido homem de criação, já notou, num artigo, que "pelo menos entre nós [publicitários], os teóricos raramente tem-se transformado em bons profissionais". E exemplifica: "É bom lembrar que um dos maiores especialistas em teoria da comunicação em nosso país, nunca conseguiu se firmar como publicitário. Quando se trata de falar sobre o assunto, ele era imbatível. Mas fazer anúncio não consegue. Tudo certinho, bonitinho, mas não funciona. Não vende. Não persuade”. (BARRETO, 2004, p.30-31)

O que temos, neste ponto, é o exemplo de uma representação que afirma ser bom profissional aquele que executa, que se volta para 
a prática, e não para as formulações teóricas - imagem que vem sendo reforçada na construção da identidade do publicitário. Esta dicotomia entre teoria e prática, aliás, encontra seu fundamento na própria academia, que divide os conteúdos, as disciplinas, as atividades, e até mesmo os docentes entre teóricos e práticos. Neusa Demartini Gomes (2005, p. 111), revela claramente esta distinção entre professores da área técnica "cuja preocupação centra-se em repassar o conhecimento gerado no mercado", daqueles que são "encarregados de transmitir fundamentos teóricos".

Não estamos dizendo, com isso, que não existem especificidades entre aspectos teóricos e práticos da profissão. $\mathrm{O}$ que questionamos, neste sentido, é a maneira distorcida com que a questão é apresentada: como se não existisse uma interdependência, uma associação direta entre os fundamentos teóricos e os aportes técnicos e práticos na formação do profissional de publicidade.

O que entendemos, neste contexto, é que existe uma tendência à valorização dos aspectos práticos que contribuem para a construção deste estereótipo do publicitário enquanto sujeito de formação eminentemente técnica. E a escola, em seu papel de formadora, se apresenta como referencial importante que reforça esta construção. Tal como reflete Neusa Demartini Gomes (2005, p. 12):

(...) atualmente, há necessidade de uma abordagem mais científica no ensino superior desta área [publicidade e propaganda] que, até agora, vinha sendo dominada pelo enfoque técnico. $\mathrm{O}$ que se sente falta é a presença, nos cursos de comunicação social que contemplam esta formação, de disciplinas que tratem a publicidade e a propaganda em seus aspectos mais teóricos (GOMES, 2005, p. 12)

Para que se entenda como se constituiu este quadro, é interessante rever o percurso histórico de institucionalização do ensino superior de Publicidade e Propaganda no Brasil. Neste sentido, percebe-se que as instituições de ensino superior na área, que nasceram da necessidade de proporcionar aos alunos "uma formação técnica e humanística que embasasse as responsabilidades sociais e econômicas da profissão" (VITALI, 2007, p. 18), reforçam esta distinção entre teoria e prática (privilegiando a segunda), uma vez que os primeiros professores dos cursos, 
renomados profissionais do mercado na época (década de 1950), foram selecionados "não pela capacidade didática, mas sim pelo conhecimento prático das matérias" (idem, p. 19).

Com o intuito de discutir a atividade publicitária e seu reconhecimento, Mariângela Toaldo faz uma reflexão a partir da teoria de Hannah Arendt sobre as relações que envolvem o trabalho humano. Toaldo caracteriza o publicitário como um profissional cujo reconhecimento próprio e perante os demais depende "da presença de outros que possam ver, ouvir e lembrar tais pensamentos, discursos e ações e, ainda, de sua materialização" (TOALDO, 2004, p. 25) .

Neste sentido, temos no publicitário, e especialmente em seu reconhecimento social, um sujeito cuja atividade é construída considerando um resultado que será observado pela sociedade. Um trabalho cujos discursos e ações são materializados (através de anúncios, produtos, campanhas) e que a partir desta materialização são vistos, reconhecidos e valorizados publicamente. Ora, se para o publicitário o seu reconhecimento e de sua atividade passam especialmente pela materialização e pela conseqüente exposição de seu trabalho, é compreensível que a técnica, a prática, tornem-se mais valorizadas que a teoria na construção da identidade deste profissional. ${ }^{1}$

Ainda considerando a reflexão da autora sobre o perfil do profissional desta área, tomando como parâmetro as convenções do "fazer publicitário" e as convicções morais circulantes no mercado, fica evidente o lugar preponderante assumido pelo trabalho e suas conquistas na vida destes sujeitos:

\begin{abstract}
Para Arendt a necessidade do trabalho, o tempo gasto no desempenho de uma atividade, o esforço pelo reconhecimento dessa atividade e para sustentar-se, a preocupação pela conquista de bens, para satisfazer as "necessidades" (de consumo) que a vida "impõe" tiram o homem do mundo: concentramse na busca por esta demanda, isolando-o na sua atividade, no seu trabalho e limitando seu convívio em outras esferas, assim como sua preocupação com relação a elas (TOALDO, 2004, p. 32).
\end{abstract}

Temos, assim, no perfil do publicitário proposto por Toaldo, a caracterização de um sujeito que tem na materialização e exposição de suas práticas (ou seja, na circulação pública dos anúncios por ele produ- 
zidos) o reconhecimento de sua atividade. Temos, ainda, a constituição de um indivíduo que muito valoriza, em sua vida, seu trabalho e seu reconhecimento pessoal e profissional. Tanto que se concentra de maneira especial à sua atividade, podendo, inclusive, isolar-se do convívio e da preocupação com as demais esferas coletivas.

Questionamos, neste sentido, o quanto esta valorização do trabalho em si e dos produtos dele resultantes, aliados ao possível isolamento e desconexão com as demais esferas sociais, não corrobora com a construção da imagem de um sujeito pouco reflexivo, cujas bases teóricas encontram-se enfraquecidas em função de uma concentração que está focada essencialmente nos aspectos práticos de sua atividade profissional.

Dito de outra maneira: percebe-se que existe um distanciamento entre o perfil ideal do profissional, tomado como parâmetro nos planos curriculares (do sujeito crítico, que posiciona-se e reflete sobre a repercussão de sua atuação profissional), e o perfil real, evidenciado no estereótipo construído tanto no mercado, quanto na sociedade. Resta procurar compreender, neste sentido, o quanto e como a escola tem interferência na construção deste cenário.

Voltando a pensar sobre o lugar da formação universitária na constituição deste profissional, consideramos a análise feita por Everardo Rocha (1995), ao investigar a partir de um estudo etnográfico alguns mecanismos de legitimação que são acionados pelos profissionais de publicidade na construção da imagem do grupo perante a sociedade. Para Rocha, dentre outros aspectos, a aprendizagem formal em nível superior é um dos pontos que formam a base desta imagem:

(...) é evidente que uma das formas mais importantes da mudança e elevação de status numa profissão é a introdução do seu estudo no nível superior, como curso universitário. Os publicitários sabem disso, pois, a despeito de críticas veementes às faculdades de comunicação, recomendam e, praticamente só aceitam candidatos deles advindos. A ambigüidade das faculdades de comunicação está em que elas são um dos pontos básicos de legitimação social da profissão e, portanto, absolutamente necessárias nesse nível (ROCHA, 1995, p. 46). 
Um aspecto evidenciado pelo antropólogo, no entanto, merece nossa atenção. Para Rocha (1995, p. 46-47), a valorização da formação em nível superior será mais importante para os publicitários enquanto instância legitimadora do profissional no mercado, do que para a prática cotidiana profissional em si. Ou seja, segundo depoimentos colhidos na pesquisa, os ensinamentos formais contribuem para um aprimoramento da visão do profissional sobre o sistema em que se enquadra a atividade publicitária, mas o curso superior não parece ser necessário, essencial, ao "fazer" publicitário. Este "saber sobre a prática", segundo publicitários depoentes da pesquisa, também pode ser aprendido no dia-a-dia, no próprio mercado de trabalho.

Diante deste contexto, é preciso analisar o quanto a aplicação real dos conhecimentos desenvolvidos na escola superior equivalem à sua função idealizada, enquanto instituição de ensino. Fica evidente, assim, a necessidade de refletir sobre o papel da universidade e o diálogo que ela consegue manter com o mercado, a sociedade e os estudantes/ profissionais (considerando, neste sentido, expectativas e relações evidentemente diferentes em cada um dos três níveis).

Ou seja, o que temos, até então, é a observação do seguinte cenário: embora as escolas historicamente venham canalizando seus esforços (currículos, atividades, investimentos) no sentido de aprimorar seus ensinamentos técnicos e práticos, estas mesmas instituições não são observadas pelos próprios publicitários como lugar onde se ensina a prática (uma vez que esta também se aprende no dia-a-dia, no mercado).

Em contrapartida, ao ser detectada a necessidade de uma abordagem mais científica no ensino superior da área, em função de uma predominância do enfoque técnico (GOMES, 2005), percebemos um enfraquecimento do aporte teórico na formação dos profissionais que estão no mercado que, em razão disso, não reconhecem devidamente a necessidade das teorias na sua atividade profissional.

Com este cenário em vista, entendemos que estamos diante de uma crise que tensiona, nestas relações, a importância e a função da escola na formação dos publicitários. Neste sentido, acreditamos que a manutenção desta dicotomia que diferencia, que põe em conflito (porque não dialogam), aspectos práticos e teóricos da profissão, contribui substancialmente para este quadro.

Para partir de um exemplo que demonstre o quanto esta distorção que desassocia teoria e prática produz entendimentos preocupantes, 
tomemos como exemplo, novamente, Roberto Menna Barreto refletindo sobre a atividade profissional do publicitário:

\begin{abstract}
O homem de criação, numa agência, como bem sabem os envolvidos no métier, não cria abstratamente, por inspiração própria (como um pintor ou um escultor), mas sim orientado por sua sensibilidade intuitiva quanto ao psiquismo dos grupos a que se dirige. Sua "audácia", sua "originalidade" nada mais são que catalizadores de elementos já plenamente presentes na constelação de valores de tais grupos. As enormes verbas envolvidas numa campanha não poderiam correr riscos de falta de sintonia com seus destinatários. O sucesso que seu autor venha a conseguir é produto menos de sua criatividade que de sua intuição passiva, perceptiva (BARRETO, 2006, p. 17).
\end{abstract}

Evidenciando, através deste exemplo, a falta de reconhecimento por parte de alguns profissionais quanto a importância das formulações teóricas no exercício prático de sua atividade, torna-se pertinente problematizar o que seria, de fato, a "sensibilidade intuitiva" ou a "intuição passiva, perceptiva” a que se refere Menna Barreto? Não estaríamos, neste caso, falando de "aprendizados" ou "modos de observar", construídos a partir de um suporte eminentemente teórico, que auxiliam este profissional a observar o seu público, na prática? E ainda, quando considera que os valores "catalizados" pelo profissional já são circulantes entre os grupos a quem a mensagem se dirige: mais uma vez não estaríamos diante de uma situação da prática em que se observa a relação direta entre publicidade, cultura e sociedade, tão cara aos estudos teóricos?

É interessante perceber que o reconhecimento da existência desta dicotomia, em si, pode contribuir para a reflexão sobre novas formas de analisar e constituir o "fazer publicitário". Deste modo, vê-se a necessidade de interrogar ambas, construções teóricas e práticas, para que se possa compreender de que maneira esta relação pode ser re-significada.

Em nosso ponto de vista, por mais que tenha se construído ao longo dos anos um conflito que distancia teoria e prática tanto na formação acadêmica quanto na atividade profissional em publicidade, percebemos que os dois aspectos sempre foram indissociáveis. O que parece fora do eixo são as formas de observar, de perceber e de evidenciar a 
congruência entre as duas instâncias. Desta maneira, considerando que a escola é palco privilegiado na necessária articulação entre teoria e prática, cabe à própria academia analisar a forma de equacionar e demonstrar esta complementaridade.

Neste sentido, entendemos que a escola deve rever, primeiramente, o quanto sua postura reforça esta idéia de incongruência entre os dois aspectos a partir, como já dito, de uma distinção que separa disciplinas, atividades e docentes entre teóricos e práticos. Neste último exemplo, é possível afirmar que a instituição de ensino contribui significativamente com esta dicotomia, ao distinguir seu corpo docente entre aqueles que são "provenientes do mercado" e cujos ensinamentos são voltados para este fim, daqueles que tem perfil mais "intelectualizado", cuja carreira profissional é voltada para a academia e para a pesquisa. A partir desta informação distintiva dos perfis docentes, nos remetemos a uma consideração sobre o perfil do profissional pretendido pela escola e esperado pelo mercado e pela sociedade:

O homem de propaganda tem que ser informado com todo tipo e toda espécie, seja acadêmica, técnica e até amenidades e reunir uma bagagem cultural sólida, que englobe a história da arte clássica e moderna, literatura, filosofia, teatro, cinema e conhecer os principais movimentos culturais (PETIT apud VITALI, 2007, p. 24).

Desta forma, parece que estamos diante de uma incoerência que precisa ser revista: se o perfil do egresso que a escola pretende formar é cada vez mais abrangente e complexo, como ela reproduz, dentro de sua própria estrutura, a categorização e distinção de seus profissionais docentes a partir do saber específico, setorizado? Esta formação mais abrangente não deveria ser reflexo da atuação de professores também mais abertos ao diálogo necessário entre saberes teóricos e práticos?

Um outro aspecto que nos parece importante para tornar esta relação coerente e evidente durante o percurso da formação acadêmica, diz respeito à desmistificação sobre a "aplicabilidade" da teoria. Sobre este tema, aliás, é recorrente a reivindicação dos acadêmicos que não reconhecem "onde" ou "de que forma" os conhecimentos teóricos serão "aplicados", na sua prática profissional - postura que, evidentemente, 
nasce da idéia de que ambas, teoria e prática, seguem percursos distintos durante a sua formação e atuação profissional.

A idéia de "aplicar a teoria na prática" para que fique evidente a sua "função" no exercício profissional nos parece equivocada, para não dizer temerosa. Esta noção faz parte de uma visão linear sobre construção do conhecimento. Neste sentido, recorremos a Pedro Demo, cuja proposta de fazer refletir sobre a complexidade do conhecimento e da aprendizagem não lineares, nos convida a rever alguns modelos de educação e a forma como se compreende o conhecimento. Para o autor, a escola reprodutiva vê o conhecimento a partir do processo linear, em que "o professor fala, o aluno escuta, toma nota e devolve na prova" (DEMO, 2002, p. 124).

Neste modelo pedagógico linear, que responde com exatidão "onde" a teoria se aplica "na prática”, é também um modelo autoritário, que não estimula o acadêmico a "saber pensar", inovar, propor de novas maneiras a utilização de seu conhecimento no mercado de trabalho. Partindo deste contexto da escola linear e reprodutiva, questionamos: será que não reconhecemos esta realidade ao observar as escolas superiores de publicidade? Ou mais, será que não reconhecemos (ou mesmo, será que não somos) ainda hoje professores de uma escola reprodutiva? Nossa proposta, neste momento é provocar a auto-crítica, a auto-avaliação - afinal, não nos cabe avaliar se não aceitarmos ser avaliados.

Para que se reveja a atuação do professor enquanto mediador, condutor, é necessário que se entenda o processo de construção do conhecimento como contínuo, inacabado - e o professor, no seu próprio processo de formação, deve questionar, deve aguçar seu espírito crítico, e reciclar continuamente o "saber pensar", afinal, não há como incentivar o aluno a fazer algo que não ele mesmo não faça.

Assim, reconhecer que os argumentos não concluem, que as verdades se modificam, que as teorias e as disciplinas isoladas não dão conta de observar a complexidade dos saberes, seria um primeiro passo a se dar. Neste contexto, as várias visões propiciadas pela abordagem interdisciplinar, são uma necessidade. No caso da publicidade é preciso perceber a importância de diversas áreas do conhecimento ${ }^{2}$ que são basilares e só constroem sentido ao saber e fazer publicitários quando postas em diálogo, quando trabalham conjuntamente.

Em seguida é preciso rever o contexto, a intersubjetividade que compõe as relações em sala de aula, onde este conhecimento deve ser estimulado. É substancial observar o acadêmico como sujeito, cujos va- 
lores, cultura e subjetividade compõem aquela formação. Cada aluno, como sabemos, tem suas potencialidades, tem expectativas, facilidades e dificuldades próprias. Ser professor implica em saber reconhecer cada sujeito desta relação de forma a explorar e incentivar estas potencialidades, como reflete Demo (2002, p. 137):

(...) retorna o desafio quase milagroso da politicidade, no sentido de estabelecer entre professor e estudante uma relação de sutilidade supina, à medida que um depende do outro, mas buscam sua autonomia. O professor precisa aprender manejar esta arte finíssima: influir de tal modo que o aluno possa resistir e superar a influência. Em vez de alinhar-se ao que o professor diz, saber pensar, argumentar, fundamentar com mão própria. Em vez de apenas escutar e tomar nota, elaborar de modo participativo. Em vez de apenas colher dados e discursos, pesquisar para aprender a questionar. "Saber pensar" exige, em seu âmago mais característico, autonomia, emancipação, projeto próprio de vida e sociedade. Trata-se de manejo do conhecimento, mas sobretudo de politicidade do conhecimento. Vê-se por aí que é imprópria a imagem usual da relação pedagógica marcada pela aula reprodutiva. Esta é, na prática, falta de relação pedagógica, por linear e autoritária. Na relação dinâmica não linear, a relação pedagógica supõe dois sujeitos autônomos em interação naturalmente criativa, desafiadora e provocativa, eivada de negociações e pretensões de ambos os lados, em grande parte imprevisível.

É fundamental que o professor perceba a importância desta imprevisibilidade, desta não linearidade em que se forma o conhecimento. É saber ser disciplinado e indisciplinado - manejar os diferentes ritmos de aprendizagem, ser inovador, provocar a curiosidade, estimular o espírito crítico, receber críticas, envolver e estimular o aluno ao prazer do saber. Dito isto, nos parece mais coerente não corresponder de forma imediata ao anseio demonstrado pelos acadêmicos para tornar evidente, explícita, esta "aplicação" dos fundamentos teóricos na prática.

Neste sentido, deve-se trabalhar entre os próprios acadêmicos a idéia de que a teoria tem a função essencial de possibilitar ao futuro profissional um "saber pensar" que deverá ser construído durante a sua formação. E ainda, deve-se esclarecer que este "saber pensar", fruto da relação de complementaridade e interdependência entre fundamentos 
teóricos e práticos, proporcionará ao acadêmico a necessária autonomia que o torna capaz de definir, por si, as relevâncias e os caminhos adequados para gerar competências (VITALI, 2007, p. 26) que o ajudem a desenvolver-se profissional, individual e socialmente.

Temos em mente que este estímulo ao desenvolvimento dos acadêmicos como sujeitos reflexivos, autônomos e comprometidos deve auxiliar na formação de publicitários que tenham uma compreensão mais abrangente de sua inserção profissional. De modo que possam buscar nas diversas bases teóricas que compõem a construção do saber publicitário fundamentos que orientem, aprimorem e justifiquem suas práticas profissionais no cotidiano. Isto significa construir o "fazer publicitário" de modo mais responsável e crítico. O que favorece aqueles que são diretamente atingidos por estes discursos (anunciantes, mercado e sociedade), ao mesmo tempo em que fortalece a própria publicidade enquanto área de construção do conhecimento e de atuação profissional.

\section{Referências}

BARRETO, Roberto Menna. Agência de propaganda e engrenagens da história. São Paulo: Summus, 2006.

. Criatividade em propaganda. São Paulo: Summus, 2004.

BRASÍLIA. Diretrizes Curriculares Nacionais dos cursos de Filosofia, História, Geografia, Serviço Social, Comunicação Social, Ciências Sociais, Letras, Biblioteconomia, Arquivologia e Museologia. Parecer Conselho Nacional de Educação/Câmara Superior de Educação 492/2001. Aprovado em 03/04/2001.

DEMO, Pedro. Complexidade e Aprendizagem - a dinâmica não linear do conhecimento. São Paulo: Atlas, 2002.

GOLOBOVANTE, Maria da Conceição. Publicidade: o fazer-valer. Comunicação, mídia e consumo. São Paulo. Vol.2, no 3. Mar/2005. p. 139-153.

GOMES, Neusa Demantrini. Publicidade ou propaganda? É isso aí! Revista FAMECOS. Porto Alegre. no 16; dezembro/2001. 
PIEDRAS, Elisa \& JACKS, Nilda. A publicidade e o mundo social: uma articulação pela ótica dos Estudos Culturais. Contemporânea, vol. 3, no 2, Julho/Dezembro de 2005. p 197-216

ROCHA, Everardo P. Guimarães. Magia e Capitalismo: um estudo antropológico da publicidade. São Paulo: Brasiliense, 1995.

TOALDO, Mariângela Machado. O publicitário e a "sua" atividade publicitária. Comunicação, Midia e Consumo. São Paulo, v. 1, no 2. 2004, p. 20-34.

VITALI, Tereza Cristina. O desafio do ensino superior de Publicidade para o século XXI. In: PEREZ, Clotilde; BARBOSA, Ivan Santo (orgs). Hiperpublicidade: fundamentos e interfaces, V. 1. São Paulo: Thomson Learning, 2007.

\section{Notas}

[1] Não queremos dizer, com isso, que os resultados visíveis do fazer publicitário (anúncios, campanhas) não sejam precedidos de conhecimentos construídos teoricamente, de estudos que fundamentem o direcionamento, ou mensurem os resultados da comunicação publicitária. Queremos observar que, nestes termos apontados pelos autores da área, a materialidade e a exposição destes discursos ocupam maior relevância para o reconhecimento deste profissional que as bases utilizadas para o planejamento, direcionamento e constituição destas práticas.

[2] Dentre as quais, além das teorias da comunicação, citamos a psicologia, a administração, as ciências sociais e as artes como diretamente envolvidas.
* Milena Carvalho Bezerra Freire de Oliveira-Cruz Mestre em Ciências Sociais (UFRN) e Professora assistente do Departamento de Ciências da Comunicação da Universidade Federal de Santa Maria (UFSM).

\section{E-mail:}

milena.freire@terra.com.br

\section{** Juliana Petermann}

Doutoranda em Ciências da Comunicação (Unisinos) e Professora assistente do Departamento de Ciências da Comunicação da Universidade Federal de Santa Maria (UFSM).

\section{E-mail:}

jupetermann@yahoo.com.br 